\title{
Mechanical Characterization of Zirconia Ceramic Composite
}

\author{
Kelvin Chew Wai Jin ${ }^{1, *}$,Kam Dickson ${ }^{1}$, and Ramesh Singh ${ }^{2}$ \\ ${ }^{1}$ Department of Mechanical Engineering, School of Engineering, Faculty of Built Environment, \\ Engineering, Technology and Design, Taylor's University, 47500 Subang Jaya, Selangor, Malaysia. \\ ${ }^{2}$ Centre of Advanced Manufacturing \& Material Processing (AMMP), Department of Mechanical \\ Engineering, Faculty of Engineering, University of Malaya, 50603 Kuala Lumpur, Malaysia.
}

\begin{abstract}
In this day and age, zirconia ceramics are used widely in the medical field as biomaterials for the replacement of damaged body parts. This is because zirconia is one of the closest replacements for bone tissue. However, there were a few cases regarding the failure of zirconia ceramic hip transplants. To overcome this issue, composite materials are being studied as they are able to combine different properties which are not present in a material. This study of Y-TZP/stainless steel 316 composite is carried out with the idea of providing a solution for failure of zirconia implants and also an improvement in biomaterials which will benefit the biomedical world. The study aims to determine the effects on how the increasing of stainless-steel content in the composite will affect the relative density, Vickers hardness, fracture toughness and ageing resistance of the Y-TZP/stainless steel 316 composite. To carry out the research, the composite samples were prepared by mixing the powder of each samples according to their determined content with ethanol. After the powders were mixed, the powders were then pressed, followed by undergoing a Cold Isostatic Press process (CIP) and then it underwent sintering at its determined temperature. After sintering, the samples underwent grinding and polishing before being ready for testing. The outcomes of the research showed that as the sintering temperature and the content of stainless-steel increase in the composite, the fracture toughness and ageing resistance improved while the Vickers hardness and relative density decreased.
\end{abstract}

\section{Introduction}

Composite materials are being used more frequently in this modern era as it tends to enable the combination of different properties which is not present in a material. In the medical field, different materials have been used for biomaterials study as a replacement for damaged body parts. Ceramics in particular has been given close attention as it is the closest replacement for bone tissue [1]. However, ceramics does not have a high toughness when it is compared to metals. Therefore, ceramic filled metal and metal filled ceramic composites are being studied to increase the overall toughness of the replacement implants.

* Corresponding author: KelvinWaiJin.Chew@taylors.edu.my 
In this modern era, prostheses that are made of purely ceramics are slowly being replaced by composite materials [2]. This is due to the improvement of the major factors, which is the strength and durability of the prostheses. Thus, studies regarding composite materials as biomaterials are being developed rapidly.

Zirconia is a ceramic which is readily used in many different sectors, especially the medical field. It has different properties when it exists at different phases, and is usually added with stabilising agents so that the phases and characteristics do not change at different temperatures. It has a high tolerance towards corrosion, high strength, high density and also high resistance towards impact. Y-TZP (Yttria-stabilized Tetragonal Zirconia Polycrystalline) in particular is more compatible to the human body. Thus, it has been used for many years as prosthetics and has not shown negative responses. Besides that, there are many different types of stainless steel which is graded based on its mechanical properties, grade compositions and also its production specifications. Generally, compared to ceramics, stainless steel has a high corrosion resistance, high toughness, high ductility and high strength. To produce implants which should be more durable, composite materials can be used to replace ceramics.

Based on the study done by Kurtz et al.[3], composite materials such as zirconia toughened alumina is better compared to materials such as zirconia and alumina as it is able to combine both the advantageous properties of alumina and zirconia. The addition of both alumina and zirconia results in having a higher fracture toughness and strength which reduces the probability of dislocation and impingement which leads to failure of implants. It also reduces the hardness which exist in ceramics. The stress-assisted degradation will also be reduced drastically while the wear characteristics improves. The study showed that the use of composite materials would allow the implants to last for a longer duration compared to ceramics without the need to be revised.

Agudelo et al.[4] did a study to determine the relative density of composite materials, zirconia and 316 stainless steel with varied compositions and heating rates. The relative density of the samples was tested with different heating rates during sintering and the results showed that, when the content of stainless steel in the samples are below $50 \%$, the relative density of the samples decreased as the heating rates increased. On the other hand, when the content of stainless steel in the samples were above $50 \%$, the relative density of the samples increased as the heating rates increased.

Esteban et al. [5] conducted a study to determine the Vickers hardness and the fracture toughness of zirconia/stainless steel composites. The zirconia/stainless steel composites were made into samples with stainless steel concentrations ranging from 15 to $30 \%$. The results of Esteban et al. [5] study showed that the Vickers hardness decreased and the fracture toughness increased as the stainless-steel content in the zirconia/stainless steel composites increased which follows the rule of mixture [6-8]. The results also showed that there was no plastic deformation when fractures occur in the zirconia/stainless steel composite samples. Besides that, the study also showed that the zirconia/stainless steel is not brittle compared to zirconia ceramic. These characteristics are important for the enhancement of materials used in biomedical implants, especially zirconia.

In the past, the medical field has reported a few cases regarding the failure of zirconia ceramic hip transplants. To overcome the issue, more and more studies have been carried out regarding the sintering of zirconia composites at low temperatures regarding its mechanical characteristics [9]. Regarding hip transplants, most of the studies carried out involve around the zirconia (Y-TZP) ceramic. In this study, the zirconia ceramic (Y-TZP) was mixed with stainless steel (316) to produce composite materials. The present paper aims to determine the relative density, Vickers hardness, fracture toughness and ageing resistance of the composite at different sintering temperatures. This study is carried out 
with the idea to enhance and aid the current medical field with an alternative solution regarding the production of transplants using different composite materials.

\section{Methodology}

\subsection{Powder preparation}

During the first stage of study, stainless steel 316 and Y-TZP powder were used based on Table 1. The stainless steel 316 powder and the Y-TZP powder were mixed and measured according to the content of stainless-steel for the preparation of the samples. Firstly, the digital ultrasonic bath (Powersonic UB-410, Thermoline Scientific, Australia) was filled with water. Then, $100 \mathrm{ml}$ of ethanol was poured into a beaker and both the stainless steel 316 powder and the Y-TZP powder were added into the beaker to undergo mixing. The weight percentage of each samples were fixed with the content of stainless steel ranging from $0 \mathrm{wt} \%, 10 \mathrm{wt} \%, 20 \mathrm{wt} \%$ and $30 \mathrm{wt} \%$ before both the powders were mixed. The beaker was placed in the Digital Ultrasonic Bath for 15 minutes and then taken out after the mixing was completed. The mixture then underwent attrition milling using the Laboratory Attritor Mill (01-HD, Union Press, United States) for 45 minutes at $500 \mathrm{rpm}$. Both the stainless steel 316 and Y-TZP powder mixture were reduced to a slurry. After mixing, the mixture was placed in a universal oven (UN 55, Memmert, Germany) overnight at $60^{\circ} \mathrm{C}$ and was left to dry. A sieve of $212 \mu \mathrm{m}$ was then used to sieve the mixture through to ensure that the powder mixture was fine.

\subsection{Green sample preparation}

The composite powders were then pressed using a hydraulic bench press (HP10-150, RMS Hydro, Malaysia) to form round tablets that have a diameter of $20 \mathrm{~mm}$. Pressing was required to form a green body and ensure that the powder mixture was fine before cold isostatic pressing. Cold isostatic pressing was carried out using a cold isostatic press (KJYU150, Shanxi Golden Kaiyuan Co., Ltd, China) and was done by placing the green body round tablets into containers of the desired shape and under room temperature and a high pressure. This was done to ensure that the green body samples were not affected by heat or pressure when they were being pressed together. If heat or pressure was applied to the green body samples as it was being pressed together, the green body samples might have cracks after they were pressed together.

Table 1. Characteristics of Starting Powders.

\begin{tabular}{|c|c|c|c|c|}
\hline Materials & $\begin{array}{c}\text { Composition } \\
(w t \%)\end{array}$ & $\begin{array}{c}\text { Theoretical } \\
\text { density } \\
\left(\mathrm{g} / \mathrm{cm}^{3}\right)\end{array}$ & $\begin{array}{l}\text { Tap density } \\
\quad\left(\mathrm{g} / \mathrm{cm}^{3}\right)\end{array}$ & $D_{50}(\mu \mathrm{m})$ \\
\hline Stainless Steel 316 & $\begin{array}{l}17 \mathrm{Cr}-12 \mathrm{Ni}-2.5 \\
\mathrm{Mo}-1 \mathrm{Si}-2 \mathrm{Mn}\end{array}$ & 8.00 & 4.4 & $21.9 \pm 0.1$ \\
\hline Y-TZP & $5.2 \mathrm{Y}_{2} \mathrm{O}_{3}$ (yttria) & 6.10 & 6.0 & $0.6 \pm 0.1$ \\
\hline
\end{tabular}

\subsection{Sintering, grinding and polishing}

The next stage of the study was where the samples underwent sintering to become specimens which were ready for testing. The samples underwent sintering by being placed into an electric box furnace (LT01, LT, Malaysia) and was heated with different 
temperatures which are $1250^{\circ} \mathrm{C}, 1300^{\circ} \mathrm{C}, 1400^{\circ} \mathrm{C}$ and $1500^{\circ} \mathrm{C}$. The sintering rate was $10^{\circ}$ per minute and the sintering process had a holding time of 2 hours. Grinding paper was then used to polish and grind the samples after sintering. The type of grinding paper used was silicon carbide ( $\mathrm{SiC}$ ) paper. 5 different grades of grinding papers, namely 120, 240, 600, 800 and 1200 were used to ensure that the samples were grinded properly. After grinding, the samples underwent polishing. There were 2 different sizes of diamond bits from the diamond paste which were used, namely $6 \mu \mathrm{m}$ and $1 \mu \mathrm{m}$. The samples were polished using the diamond paste on a polishing clothe. Both the grinding and polishing process were carried out using a polishing and grinding machine (GP2V, LT, Malaysia).

\subsection{Measurement and Analysis}

\subsubsection{Relative density}

After the samples were prepared, a series of different test were conducted on the samples to determine different mechanical properties. To determine the relative density of the composite samples, the water immersion technique using an analytical balance with density kit (AY220, Shimadzu, Japan) was used while the immersion medium was distilled water. The technique was done based on Archimedes principle. The theoretical density of Y-TZP was determined as $6.1 \mathrm{Mg} \cdot \mathrm{m}^{-3}\left(\right.$ or $\left.\mathrm{g} / \mathrm{cm}^{3}\right)$. The formula for the calculation of relative density is based on (eq 1).

where

$$
\rho=\frac{w_{a}}{w_{a}-w_{w}} \rho_{w}
$$

$$
\begin{array}{lll}
\rho & = & \text { Relative density of sample }\left(\mathrm{g} / \mathrm{cm}^{3}\right) \\
w_{a} & =\text { Weight of sample in air }(\mathrm{g}) \\
w_{w} & =\text { Weight of sample in water }(\mathrm{g}) \\
\rho_{w} & = & \text { Density of distilled water }\left(\mathrm{g} / \mathrm{cm}^{3}\right)
\end{array}
$$

\subsubsection{Vickers hardness}

The Vickers hardness of the samples was tested using a Vickers hardness tester (MV-01, Matsuzawa, Japan) which had a pyramidal diamond indenter and an applied load of $10 \mathrm{~kg}$. The load was applied on to the samples slowly without impact and was held down in place on the sampled for a duration of 10 seconds. The physical quality if the indenter and the accuracy of the applied load was defined based on ASTM E284-99 [10] and ISO 14705 [11] and shown in Figure 1. After the indentation was done, the indentation was measured using a filar micrometer which was built in the attached microscope on the Vickers hardness machine. The microscope had an accuracy nearest to $0.1 \mu \mathrm{m}$. The formula for the calculation of the Vickers's hardness is presented in (eq 2).

where

$$
H_{v}=\frac{1.854 P}{(D)^{2}}
$$

$P \quad=\quad$ Applied load $(\mathrm{kg})$

$D=$ Average of two diagonals $D_{1}$ and $D_{2}(\mathrm{~m})$ 


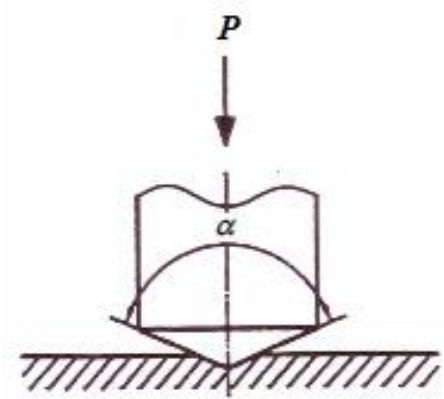

(a)

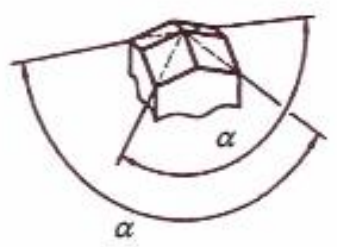

(b)

Fig. 1. Schematic diagram showing the shape of the Vickers indenter $\left(\alpha=136^{\circ} \pm 0.5^{\circ}\right.$, angle between the opposite faces at the vertex of the pyramidal indenter) and (b) an indentation that is formed [11].

\subsubsection{Fracture toughness}

After the indentation was done on the sample, the fracture toughness was also measured based on the same indentations that were used to determine the Vickers hardness. The equation to calculate the fracture toughness is presented in (eq 3) which was proposed by Niihara et al. [12]. Selected parameters from Vickers indentation are depicted in Figure 2.

where

$$
\left(\frac{K_{I C^{\Phi}}}{H_{V} a^{\frac{1}{2}}}\right)\left(\left(\frac{H_{V}}{E \Phi}\right)^{\frac{2}{5}}\right)=0.035\left(\left(\frac{L}{a}\right)^{\frac{-1}{2}}\right)
$$

$K_{I C}=$ Fracture toughness $\left(\mathrm{MPa} . \mathrm{m}^{1 / 2}\right)$

$H_{V}=$ Vickers hardness (GPa)

$E=$ Young's Modulus $(\mathrm{GPa})$, taken as $200 \mathrm{GPa}$ for Y-TZP ceramic

$a=$ Half-length of the average diagonal (m)

$L=$ Average crack length (m)

$\Phi=$ Constraint factor taken as 3 [13] 


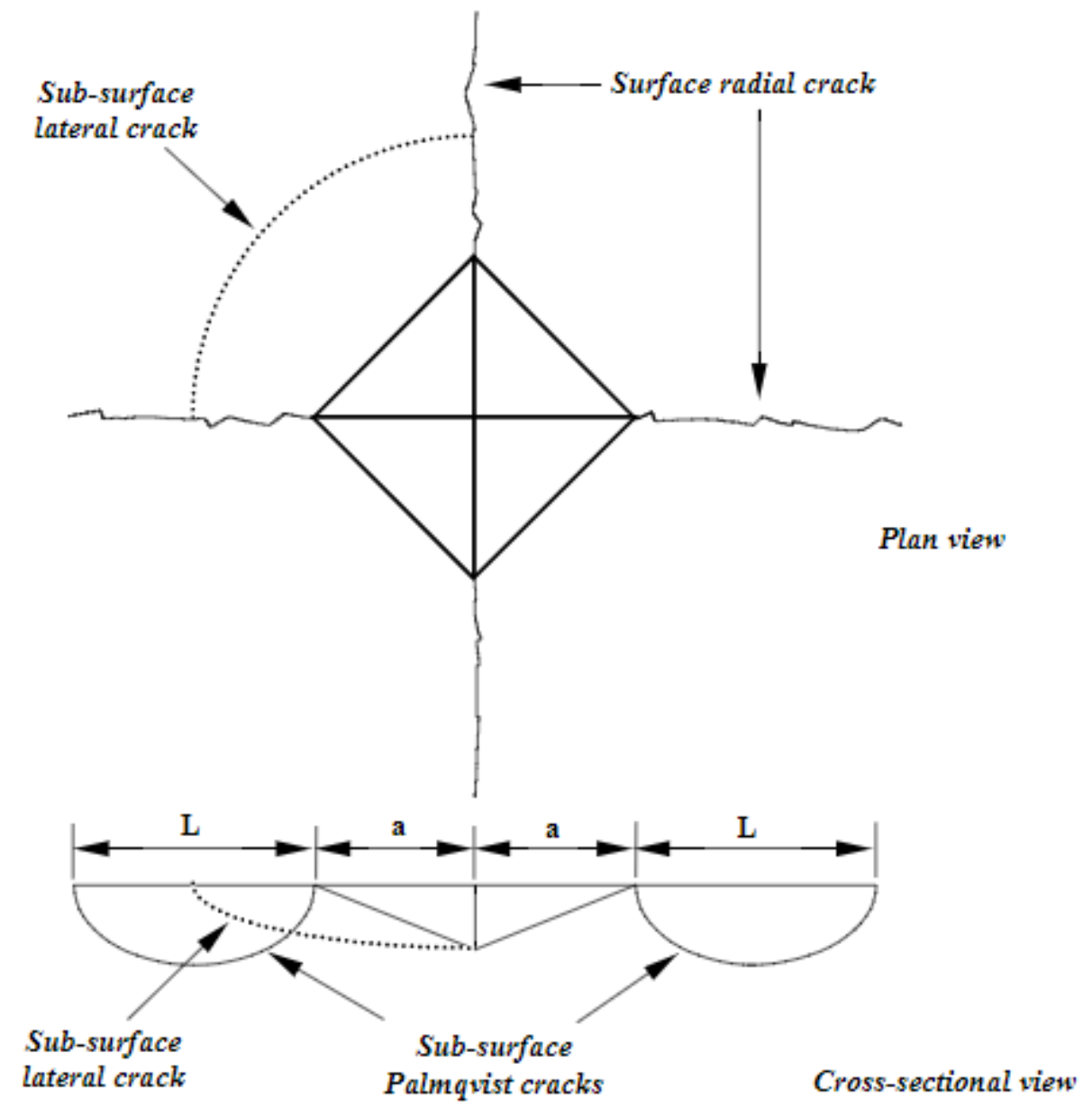

Fig. 2. Schematic diagram of a typical Palmqvist crack system observed after Vickers indentation. " $L$ " refers to the crack length which was measured to compute the fracture toughness of the sample while the length of " $2 a$ " is equivalent to a diagonal of the Vickers indent $\left(D_{I}\right.$ or $D_{2}$, as indicated in Fig. 1).

\section{Results and Discussion}

\subsection{Relative Density}

The relation between relative density and the sintering temperature of the composite material is shown in Figure 3. It is shown that, for the samples which contain 10 and 20 weight percentage of stainless steel $316 / \mathrm{Y}-\mathrm{TZP}, 1300{ }^{\circ} \mathrm{C}$ is the optimum sintering temperature as it has its highest relative density. As for the sample which contained 30 weight percentage of stainless steel $316 / \mathrm{Y}-\mathrm{TZP}$, the relative density increases as the sintering temperature increases from $1250{ }^{\circ} \mathrm{C}$ to $1500{ }^{\circ} \mathrm{C}$. For the sample which contains pure Y-TZP, it has the highest relative density when the sintering temperature was $1400{ }^{\circ} \mathrm{C}$. The results showed that pure Y-TZP had a higher relative density compared to composite 
materials of ss316/Y-TZP at higher sintering temperatures. Besides that, it also showed that as the weight percentage of stainless steel in the composite material increased, the relative density of the composite material decreased. The results obtained also showed that it was in line with the findings based on the study of Agudelo et al. [4] to a certain extent.

Based on Agudelo et al. [4] study, as the weight percentage of stainless steel in ss316/Y-TZP samples increase, the relative density of the samples increased over sintering temperatures. This is true theoretically as the heating rates and temperatures increase, the density if the samples with increasing weight percentage of stainless steel increases. However the trend of the study suggested otherwise. When the percentage of stainless steel 316 increased past $10 \mathrm{wt} \%$, the relative density decreased. This can be explained due to a few factors. Firstly, the method of processing for the samples in this study and the study carried out by Agudelo et al. [4] was different; thus, the processing method could have an effect on the results obtained. Another possibility could be attributed to the type of powder used in the study. To have a better understanding regarding the difference in trends, further study regarding microstructure examination via scanning electron microscope (SEM) is required.

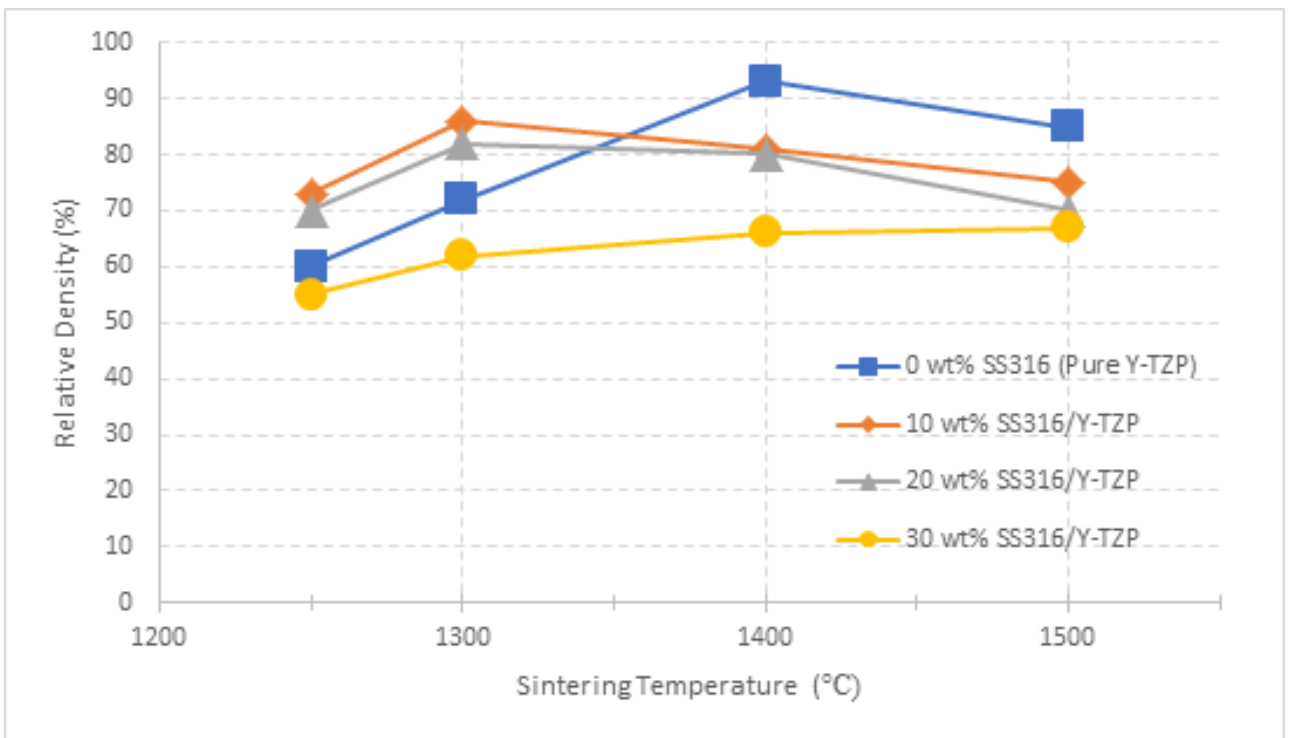

Fig. 3. Relative density of ss $316 / Y-T Z P$ composites with different stainless steel ss 316 contents sintered at various temperatures.

\subsection{Vickers Hardness}

Figure 4 shows the relation between sintering temperature and the Vickers hardness of the composite material. Based on Fig. 4, pure Y-TZP had the highest Vickers hardness which is $13.5 \mathrm{GPa}$ when its sintering temperature is $1400{ }^{\circ} \mathrm{C}$. However, all the composite materials with different weight percentage of stainless steel had the highest Vickers hardness at the sintering temperature of $1300{ }^{\circ} \mathrm{C}$. This showed that the ideal sintering temperature for the stainless steel $316 / \mathrm{Y}$-TZP composite was $1300{ }^{\circ} \mathrm{C}$. It is also shown based on the results that when the weight percentage of stainless steel 316 in the stainless steel 316/Y-TZP composite increases, the Vickers hardness of the composite material will reduce. This is also true based on the study of Esteban et al. [5] which showed the same 
results compared to Figure 3. This can be explained due to the hardness of materials as stainless steel 316 is softer than Y-TZP, which also obeys the rule of mixture [6-8].

The trend in this study is similar to the trend of Esteban et al. [5] study. The reduction in Vickers hardness can be explained based on the hardness of ss316 and Y-TZP. Stainless steel 316 is softer compared to Y-TZP; thus, when the content of the ss316 in the ss $316 / Y$ TZP composite increases, the Vickers hardness will reduce as the hardness of ss $316 / Y-T Z P$ composite is lower as the composition has higher amounts of stainless steel which will also cause the composite to be softer.

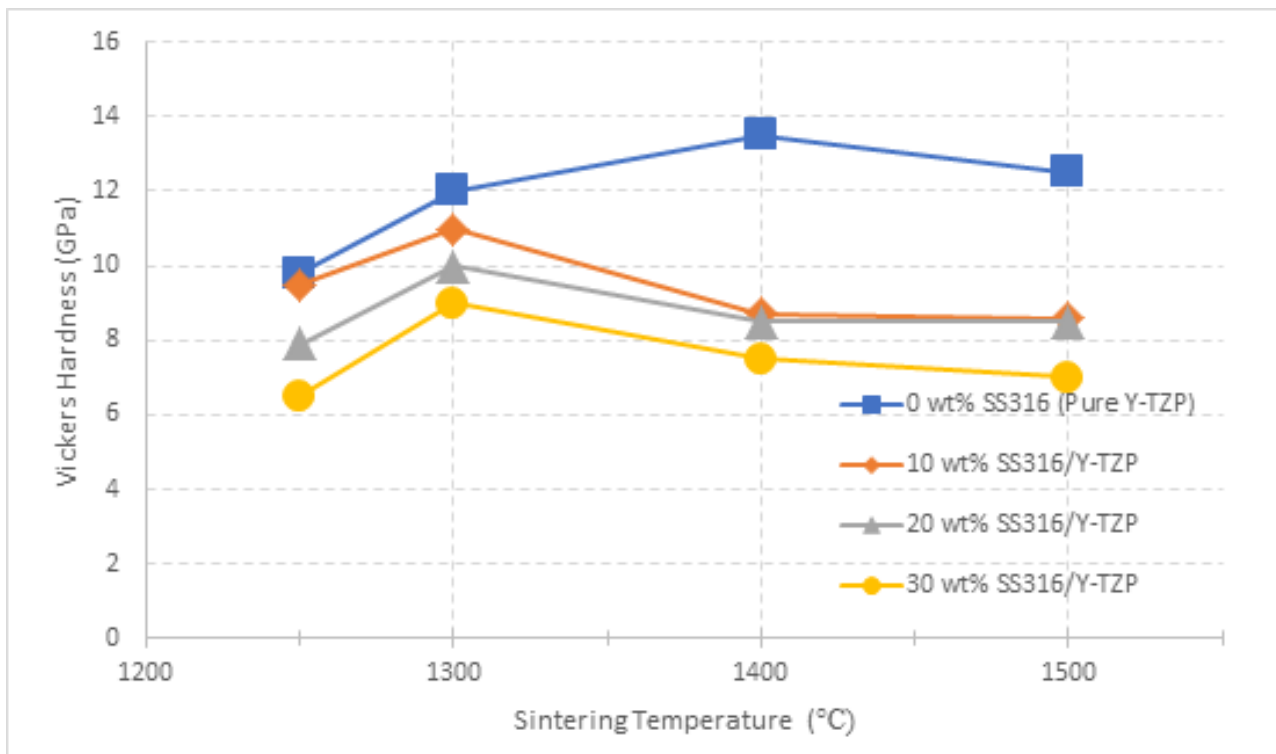

Fig. 4. Effect of increasing sintering temperature on the Vickers hardness of ss316/Y-TZP composites containing 0 to $30 \mathrm{wt} \%$ stainless steel ss 316 content.

\subsection{Fracture Toughness}

Figure 5 exhibits the results of the fracture toughness of different weight percentage of ss316/Y-TZP at different sintering temperatures. Based on the results from Figures. 3, 4 and 5, it showed that once again the ideal temperature for sintering of 10 and 20 weight percentage ss $316 / \mathrm{Y}-\mathrm{TZP}$ is $1300^{\circ} \mathrm{C}$. At $1300^{\circ} \mathrm{C}$, both the 10 and 20 weight percentage ss316/Y-TZP had the highest fracture toughness. The results also showed that the composite materials which contained stainless steel had lower fracture toughness as the sintering temperature increased after $1300{ }^{\circ} \mathrm{C}$. The results also showed that when the weight percentage of stainless steel in the composite increased, the fracture toughness also improved. However, this is only from $0 \mathrm{wt} \%$ to $20 \mathrm{wt} \% \mathrm{ss} 316 / \mathrm{Y}-\mathrm{TZP}$.

The trend of the results appeared somewhat similar to the results obtained by studies done by Esteban et al. [5]. For the 10 and $20 \mathrm{wt} \%$ ss $316 / Y-T Z P$ samples, when the number of stainless-steel 316 particles increases in the composite, mismatched thermal expansions will occur between both the zirconia and stainless-steel particles and result in radial tensile stresses to be developed internally when cooling occurs. This in turn causes debonding to happen due to the lack of interfacial bonds between the particles. When cracks happen, the cracks will propagate smoothly between the weak interface of the zirconia and stainlesssteel particles which in turn produce crack deflection processes that improves that fracture 
toughness [5]. Figure 6 shows the crack propagation across the Y-TZP and metal. However, for the $30 \mathrm{wt} \% \mathrm{ss} 316 / \mathrm{Y}$-TZP, the number of stainless steel 316 particles in the composite is too large which causes mismatched thermal expansions that form thermal stresses in the composite material which is too large, causing the fracture toughness to reduce.

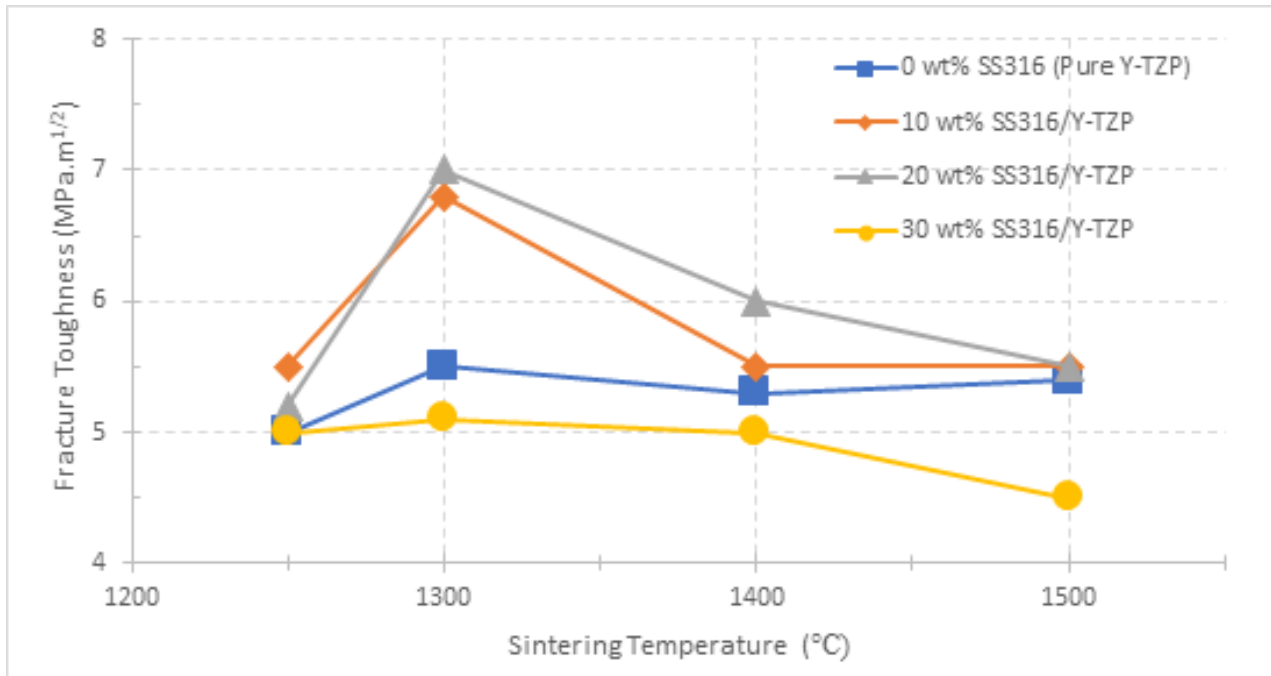

Fig. 5. Fracture toughness of ss $316 / \mathrm{Y}$-TZP composites sintered at various temperatures from $1250^{\circ} \mathrm{C}$ to $1500^{\circ} \mathrm{C}$.

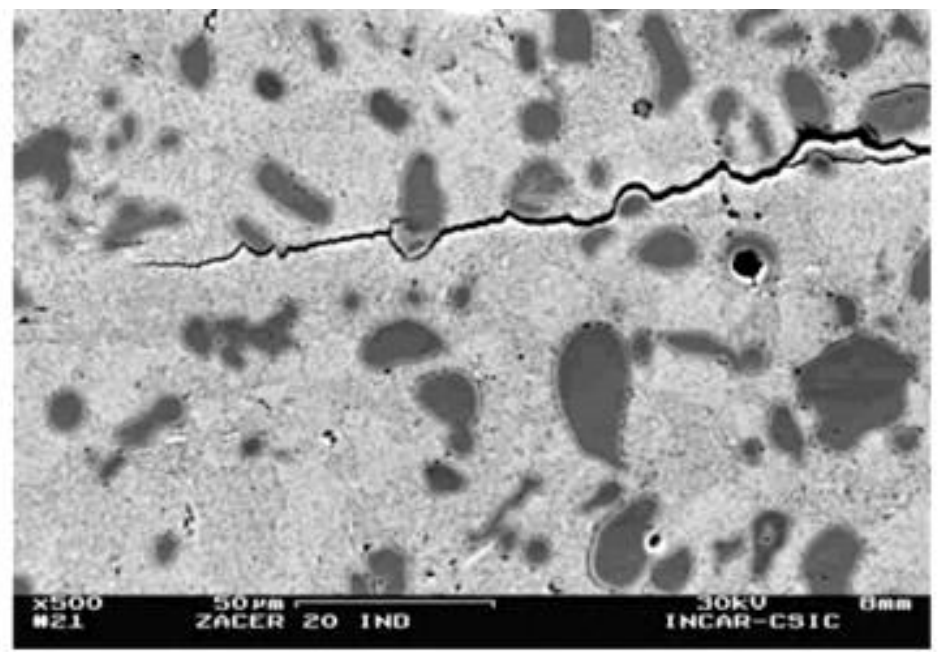

Fig. 6. SEM micrograph showing the propagation of a crack, induced by Vickers indentation, across the microstructure of a stainless steel/zirconia composite. Areas of lighter shade refer to zirconia while the darker phase refers to metal [5]. 


\section{Conclusion}

The mechanical characteristics of stainless steel 316/Y-TZP composite were studied through relative density, Vickers hardness and fracture toughness testing. Based on the results, it is shown that the ideal weight percentage of stainless steel 316 in the stainless steel $316 / \mathrm{Y}$-TZP composite is $20 \mathrm{wt} \%$. The results also showed that $30 \mathrm{wt} \%$ of stainless steel would result in the reduction of mechanical characteristics. Besides that, the ideal sintering temperature for the stainless steel $316 / \mathrm{Y}$-TZP composite is $1300{ }^{\circ} \mathrm{C}$ as any temperature above that would result in deterioration of its mechanical characteristics. It is also found that the increase in stainless steel 316 weight percentage in the ss316/Y-TZP composite will result in areduction in relative density and Vickers hardness. However, the Vickers hardness of the composite will still be lower compared to pure Y-TZP.In addition to that, an increase in stainless steel 316 weight percentage in the ss316/Y-TZP composite will also result in an improvement in fracture toughness.

\section{References}

1. M.M. Stevens, Mater. Today, 11, 18-25 (2008).

2. S.D. Heintze, A. Cavalleri, G. Zellweger, A. Büchler, G. Zappini, Dent. Mater., 24, 1352-1361 (2008).

3. S.M. Kurtz, C. Arnholt, R. Huet, M. Ueno, W.L. Walter, J. Mech. Behav. Biomed. Mater., 31, 107-116 (2014).

4. L. Grajales Agudelo, V.L. Arantes, P.L. di Lorenzo, Adv. Powder Technol., 802, 120124 (2014).

5. S. Lopez-Esteban, J.F. Bartolome, C. Pecharroman, S.R.H. Mello Castanho, J.S. Moya, Mater. Res., 4, 217-222 (2001).

6. F.F. Lange, J. Mater. Sci., 17, 247-254 (1982).

7. V.D. Krstic, W.H. Erickson, J. Mater. Sci., 23, 4097-4102 (1988).

8. A.H. De Aza, J. Chevalier, G. Fantozzi, M. Schehl, R. Torrecillas, Biomater., 23, 937945 (2002).

9. G. Schierano, F. Mussano, M.G. Faga, G. Menicucci, C. Manzella, C. Sabione, T. Genova, M.M. Von Degerfeld, B. Peirone, A. Cassenti, P. Cassoni, S. Carossa, Biomed. Res. Int., 2015, Article ID 157360 (2015).

10. ASTM E384-99, "Standard Test Method for Microindentation Hardness of Materials," Annual Book of ASTM Standards (1999).

11. ISO 14705, "Fine ceramics (advanced ceramics, advanced technical ceramics) - Test method for hardness of monolithic ceramics at room temperature" (2000).

12. K. Niihara, R. Morena, D.P.H. Hasselman, J. Mater. Sci. Letts., 1, 13-16 (1982).

13. R.N. Katz, Mater. Sci. Eng., 71, 227-249 (1985). 